\title{
Infância e adolescência: como chegam as queixas escolares à saúde mental?
}

\section{Childhood and adolescence: how do school complaints arrive at the mental health service?}

\author{
Cristiana Carneiro ${ }^{1}$ \\ Luciana Gageiro Coutinho ${ }^{2}$
}

\begin{abstract}
RESUMO
O presente trabalho discute os resultados de um estudo piloto realizado entre janeiro e junho de 2012 no Serviço de Psiquiatria da Infância e Adolescência do Instituto de Psiquiatria da UFRJ. De caráter exploratório, através de análise documental, o estudo rastreou queixas ligadas à escolarização dentro do universo dos casos atendidos na triagem do referido período. Tem como objetivo, portanto, mapear as queixas escolares registradas na porta de entrada de um serviço universitário de psiquiatria. Apresenta as principais queixas provenientes de encaminhamentos feitos pela escola à saúde mental voltada para infância e adolescência, a partir de 285 fichas de triagem, bem como analisa idade e gênero da entrada no serviço. Discute, ainda, como são descritas as queixas escolares a partir de seis relatos de triagem, apontando para a importância em se destacar o contraditório na queixa inicial. Conclui que aproximadamente um terço do público que chega ao referido serviço de psiquiatria da infância e adolescência apresenta queixas iniciais envolvendo escolarização, sendo dificuldade de aprendizagem e agitação as prevalentes.

Palavras-chave: infância; adolescência; saúde mental; queixa escolar.
\end{abstract}

DOI: $10.1590 / 0104-4060.37764$

1 Universidade Federal do Rio de Janeiro. Faculdade de Educação. Rio de Janeiro, Rio de Janeiro, Brasil. Av. Pasteur. Botafogo. CEP: 22290-902.E-mail: cristianacarneiro13@gmail.com

2 Universidade Federal Fluminense, Faculdade de Educação. Niterói, Rio de Janeiro, Brasil. Campus do Gragoatá. Bloco D, 4ºndar. CEP: 24210-350.E-mail: lugageiro@uol.com.br 


\begin{abstract}
This paper discusses the results of a pilot study conducted between January and June 2012 in the Department of Child and Adolescent Psychiatry, Institute of Psychiatry, at UFRJ. This is an exploratory study, through documentary analysis, which tracked complaints related to schooling within the universe of triage cases in the said period. Therefore, it had the goal of mapping school complaints that were recorded at the front door of a university psychiatry service. It presents the main complaints made by schools on mental health focused on childhood and adolescence from 285 triage records, as well as age and gender analyses based on the entry into the service. It also discusses how the school complaints are described from six triage reports pointing to the importance of the contradictory standout in the original complaint. It concludes that about one third of those seeking this service of childhood and adolescence psychiatry presents initial complaints involving schooling, then learning difficulty and agitation were prevalent.
\end{abstract}

Keywords: childhood; adolescence; mental health; school complaints.

\title{
Introdução
}

A procura pelos serviços de saúde mental voltada à infância e adolescência no Brasil apresenta uma história que se articula às demandas escolares. Segundo Cabral e Sawaya (2001), 50 a 70 por cento do contingente que procura os serviços voltados à infância alega problemas escolares, sobretudo dificuldade de aprendizagem e problemas de comportamento. Romaro e Capitão (2003) apontam que entre as crianças e os adolescentes encaminhados aos ambulatórios de psicologia predominam os relatos de queixas múltiplas, sendo mais frequentes as dificuldades escolares para as crianças e as dificuldades no relacionamento interpessoal para adolescentes. Campezatto e Nunes (2007) realizaram uma pesquisa de levantamento das características da população que buscou atendimento em 2004 nas dez clínicas-escola da Região Metropolitana de Porto Alegre. Reconheceram também a similaridade dos achados com a grande maioria das pesquisas, permitindo-se a inferência de um perfil típico da criança/adolescente que busca atendimento em clínicas-escola no Brasil: crianças, do sexo masculino, encaminhadas por escolas devido a dificuldades de aprendizagem ou comportamento.

A relação entre questões escolares e saúde mental, embora frequente, não deixa de ser bastante problemática. No final da década de 1980, Maria Helena Souza Patto, em sua conhecida tese $A$ produção do fracasso escolar, já apon- 
tava para os grandes equívocos em se individualizar as questões, reduzindo as dificuldades na escola a patologias. (PATTO, 1999). O próprio encaminhamento de questões escolares à saúde mental pode, muitas vezes, acarretar um conjunto de consequências geradoras de preconceitos que agravam a situação. (BOARINI; BORGES, 1998). Nesse sentido, compreender como chegam as queixas escolares à saúde mental e refletir sobre a temática continua sendo um desafio para aqueles envolvidos com saúde e educação.

O presente artigo é resultado de uma pesquisa em andamento e aprovada pelo Comitê de Ética em Pesquisa. Em nossa inserção inicial no IPUB (Instituto de Psiquiatria da Universidade Federal do Rio de Janeiro - UFRJ), zona sul do Rio de Janeiro, de caráter exploratório, realizamos um estudo piloto entre janeiro e junho de 2012 de rastreamento das queixas ligadas à escolarização dentro do universo de todos os casos atendidos na triagem do SPIA (Serviço de Psiquiatria da Infância e Adolescência) no referido período. Sendo um serviço de psiquiatria da infância e adolescência aonde chegam os mais variados casos, com diferentes demandas e de diferentes procedências, chama a atenção a quantidade de queixas referidas à escola. $\mathrm{O}$ presente texto consiste em uma análise feita a partir das fichas de triagem e pretendeu mapear a chegada dos usuários ao serviço naquilo que fazem menção à escola.

O estudo piloto teve, então, como objetivo o mapeamento das queixas escolares registradas na porta de entrada de um serviço universitário de psiquiatria. Orientou-se pelas seguintes questões: quantas crianças/adolescentes chegam ao serviço? Como elas chegam? Vêm indicadas por quem? Ou seja, num primeiro momento, nossa atenção voltou-se para a chegada do usuário ao serviço.

$\mathrm{O}$ estudo faz parte de um projeto de pesquisa maior que se constituiu a partir de uma parceria entre o NIPIAC (Núcleo Interdisciplinar de Estudo e Pesquisa para a Infância e Adolescência Contemporâneas), as Faculdades de Educação da UFRJ e da Universidade Federal Fluminense - UFF e o Instituto de Psiquiatria da UFRJ, onde casos em atendimento de crianças e adolescentes com dificuldades escolares são objeto de análise. Parte-se do pressuposto de que é necessário ampliar a discussão sobre as chamadas "dificuldades de aprendizagem", que não podem ser pensadas isoladas de um estudo mais cuidadoso do caso, em que sejam discutidos os múltiplos fatores que intervêm. $\mathrm{Na}$ aprendizagem, que também não pode ser pensada de forma isolada da inserção escolar, familiar e social da criança, diversos elementos interagem de modo entrelaçado regulando a relação do sujeito ao saber que se produz. O projeto maior tem como objetivo, portanto, ampliar a discussão sobre o mal-estar na escolarização de crianças/adolescentes numa vertente interdisciplinar, visando integrar vários discursos, mais especificamente, a família, a escola, especialistas e a própria criança/adolescente. 
No sentido de ampliar uma leitura sobre os impasses na escolarização, articulamos psicanálise e educação, mais particularmente o ponto de encontro e convergência refere-se ao mal-estar na escolarização. Entenda-se com isto uma ampla gama de dificuldades que envolvem a relação da criança e do adolescente com o ambiente escolar. Inserem-se aí: problemas de aprendizagem, dificuldades em relacionamentos entre pares na escola, dificuldades na relação professor-aluno, questões que envolvam leitura e escrita, agressividade e atenção, enfim, tudo aquilo que pode ser descrito como causando mal-estar na relação da criança ou adolescente com a escola.

Pain (1985, p. 13) enfatiza uma diferença entre problemas de aprendizagem e problemas escolares, estes últimos sendo mais abrangentes, envolvendo indisciplina, integração, podendo ser uma formação reativa diante de uma transição difícil do grupo familiar ao grupo social. No entanto, não utilizamos o termo problema, já que ele pressupõe a formulação de uma situação conflitiva e de entraves já com algum nível de enunciado. Ou seja, se problema reenvia a um contexto já com alguma definição, mal-estar reenvia para algo mais difuso, remetido justamente ao encontro do pulsional com a cultura. (FREUD, 1980 [1930]). Este mal-estar pode ser anunciado pela própria criança, bem como pela escola em relação à criança ou adolescente, pela família ou ainda por algum especialista cuidador desta criança ou adolescente. Destarte a queixa de mal-estar na escolarização é a prerrogativa para a pesquisa, ainda que ela seja enunciada por diferentes fontes. Uma criança pode, por exemplo, não apresentar nenhum problema de rendimento escolar, não tendo sido apontados problemas de aprendizagem, no entanto, ao apresentar comportamento continuamente irrequieto, pode causar mal-estar na escola, o que reverterá para ações que envolvem diretamente a vida da criança/adolescente na escola.

$\mathrm{O}$ contato do SPIA com nosso núcleo partiu da inquietação quanto à quantidade de queixas referentes à escola no universo de crianças/adolescentes encaminhadas para o serviço e o pouco ou nenhum desdobramento mais constante em relação ao tema. Ou seja, a única ponte mais concreta entre o usuário e a escola se fazia, muitas vezes, através do medicamento.

Tanto o estudo piloto quanto a pesquisa maior se inserem no paradigma de construção de subjetividades. A pesquisa de construção de subjetividades se volta para o processo, para os modos de subjetivação, e não para o sujeito em si, como se este fosse já dado ou constituído. Ou melhor, ainda que estejamos atentos ao individual que concerne às subjetividades, portanto, partimos da ideia de sujeito, o compreendemos como inacabado, provisório. Como diz Catharino (2001, p. 46), "portanto, se podemos falar de subjetividades, o fazemos sempre referidos a um tipo de produção, coletivamente engendrada no tecido social". 


\section{Metodologia}

A análise do estudo piloto foi documental, a partir das fichas de triagem, que além dos dados de identificação (nome, endereço, idade, responsáveis) concentra-se principalmente no motivo da procura institucional. Os percentuais encontrados referem-se, então, ao primeiro registro de contato e não ao posterior encaminhamento, em que a queixa geralmente é aprofundada pelo profissional que atenderá a criança na instituição, ou reencaminhada a outro serviço. Neste sentido, o registro na triagem não significa a permanência no SPIA.

O SPIA é voltado à comunidade em geral, e qualquer pessoa pode solicitar atendimento para a criança/adolescente. Nesse sentido, a triagem - como porta de entrada - constitui-se como dispositivo essencial para compreendermos melhor a demanda pelo serviço. Na maioria das vezes, a pessoa que busca o atendimento na saúde mental faz a partir de um encaminhamento, prevalecendo o médico e o escolar. Constatamos um número expressivo de casos que chegam para a triagem com queixas já registradas como "dificuldades de aprendizagem" e "agitação".

A partir do levantamento das fichas de triagem, o estudo piloto fez com que elegêssemos duas categorias - dificuldades de aprendizagem e agitação - como critérios de elegibilidade dos casos a serem estudados na pesquisa maior. Nesta última, ainda que tenhamos três pré-requisitos fundamentais para a escolha dos casos (ser criança ou adolescente, ser atendido pela psiquiatria e apresentar alguma queixa de mal-estar na escolarização), o aprofundamento dos critérios de escolha se faz importante no sentido de tornar mais relevante a relação entre o que se pretende pesquisar e o universo pesquisado. $\mathrm{O}$ intuito do mapeamento através da pesquisa piloto era, então, compreender melhor o grupo de crianças/adolescentes que procura o SPIA de maneira mais geral, para consequentemente selecionar casos que, em sua particularidade, pudessem de alguma forma contribuir para uma reflexão estendida deste universo.

\section{Resultados}

Em um total de 285 casos atendidos na triagem no período de seis meses da pesquisa piloto, 92 casos chegaram com alguma queixa referida à escola. Portanto, aproximadamente um terço $(32,29 \%)$ da procura relaciona problemas que envolvem a escola de alguma forma. Dentre estes, 44 apresentaram queixas 
de dificuldades de aprendizagem e 30 de agitação/inquietude, de forma que estas duas categorias mostraram-se prevalentes. Em alguns casos elas se encontram vinculadas, em outros apenas uma delas é referida. Ainda aqui, é importante salientarmos que dos 92 casos com queixas referidas à escola, 43 apresentaram a escola como "identificadora" dos problemas atribuídos nos registros. Ou seja, a escola ocupa um lugar bastante expressivo, como aquela que identifica e encaminha a criança/adolescente para o setor de psiquiatria da infância/adolescência. Além das queixas prevalentes encontramos problemas de humor, dificuldades na leitura e escrita, entre outros, especificados no quadro a seguir:

\section{GRÁFICO 1 - QUEIXAS APRESENTADAS NOS CASOS ANALISADOS}

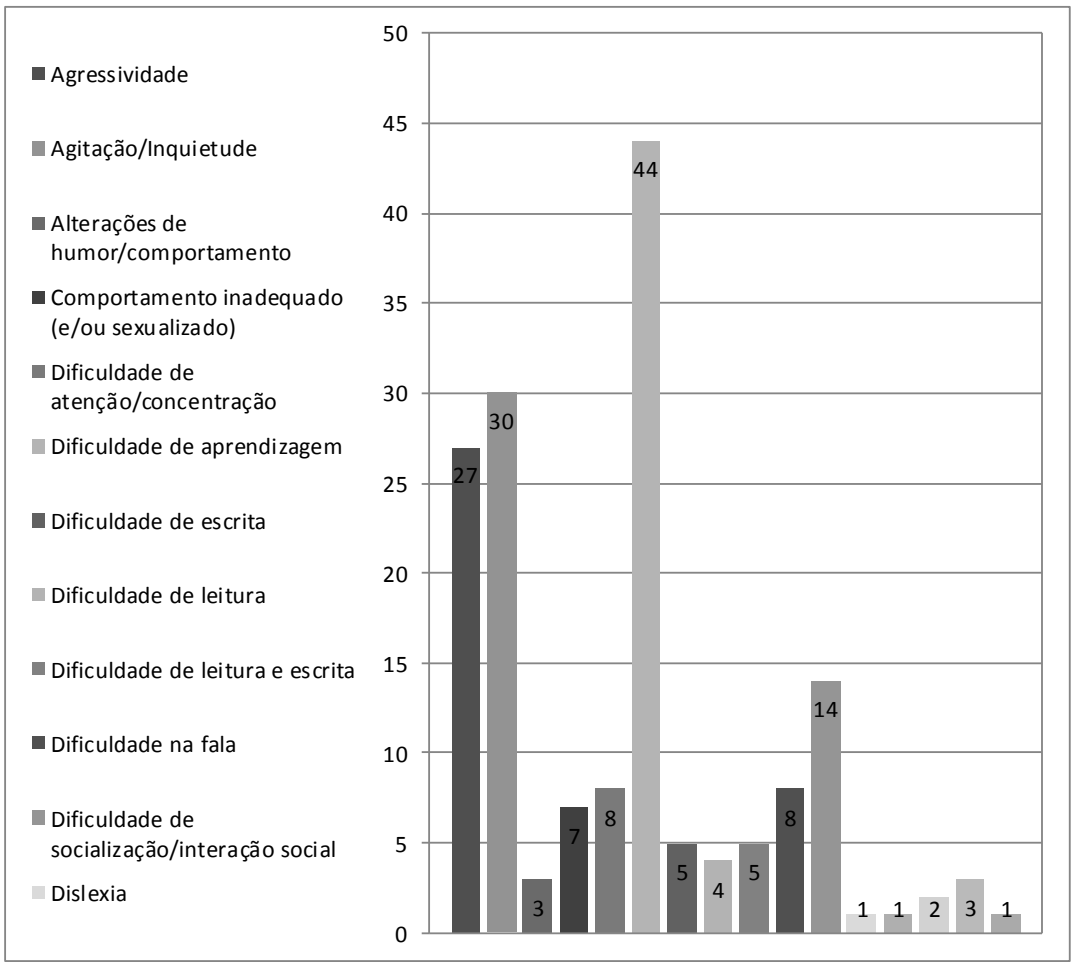

FONTE: O autor (2013). 
Em relação à ocorrência de casos por faixa etária e gênero, confirma-se a literatura internacional que indica uma procura maior, na psiquiatria da infância e adolescência, referida ao sexo masculino. (MELLO; MELLO; KOHN, 2007). Em termos de faixa etária, em ambos os gêneros podemos indicar a faixa dos sete aos dez anos como a mais procurada. Este resultado indica uma relação importante com a trajetória escolar, já que é nesta faixa de idade que se espera o aprendizado da leitura/escrita, que envolve aquisições complexas. Memória, atenção, coordenação motora, enfim, requisitos que colocam muitas vezes em xeque a maneira como a criança vinha vivendo até então. A partir dos treze anos encontra-se novamente aumento na procura pelo serviço, ainda que menor à dos sete aos dez, coincidindo com a entrada na adolescência.

Um ponto importante a ressaltar quanto à faixa etária, ainda que numericamente pouco prevalente, é o encaminhamento de crianças por "dificuldade de aprendizagem" na faixa de três anos de idade. Por que a escola está nomeando a queixa desta forma com crianças nesta faixa etária não é claro, mas chama a atenção, já que aprendizagens específicas como as que envolvem alfabetização e matemática ainda não são exigidas. Vejamos, a seguir, a idade e gênero referidos nas fichas de triagem dos que deram entrada no SPIA no primeiro semestre de 2012.

\section{QUADRO 1 - OCORRÊNCIA DE CASOS POR FAIXA ETÁRIA X GÊNERO}

\begin{tabular}{|c|c|c|c|c|c|c|c|c|c|c|c|c|c|c|c|}
\hline Idade (anos) & 3 & 4 & 5 & 6 & 7 & 8 & 9 & 10 & 11 & 12 & 13 & 14 & 15 & 17 & $\begin{array}{c}\text { TOTAL } \\
\text { (casos) }\end{array}$ \\
\hline Feminino & - & - & - & 1 & 1 & 3 & 3 & - & 1 & 5 & 2 & - & - & 1 & 17 \\
\hline Masculino & 1 & 3 & 3 & 5 & 8 & 9 & 11 & 10 & 4 & 3 & 7 & 5 & 2 & 4 & 75 \\
\hline $\begin{array}{l}\text { Total (faixa } \\
\text { etária) }\end{array}$ & 1 & 3 & 3 & 6 & 9 & 12 & 14 & 10 & 5 & 8 & 9 & 5 & 2 & 5 & 92 \\
\hline
\end{tabular}

FONTE: O autor (2013).

Como podemos ver, as idades que abrangem o período escolar demonstram uma procura maior. Como já foi dito, as crianças a partir dos sete anos foram muitas vezes encaminhadas pela escola. Em quase metade dos casos $(46,73 \%)$ a escola identifica "problemas" que acredita concernirem à saúde mental. 


\section{Queixas escolares}

Nas fichas de triagem, as queixas são registradas sempre por um médico. Mas como são descritas as queixas na ficha de triagem? Que pontos podem ser destacados por nós, pesquisadores interessados nas questões que envolvem a escola? Em se tratando de uma ficha de triagem, portanto, de informações colhidas em uma entrevista inicial que decidirá os rumos do encaminhamento, elegemos como estratégia analítica o paradoxo. Ao apontar o contraditório, o paradoxo oferece a possibilidade de questionamento de uma declaração aparentemente verdadeira, favorecendo a problematização e a ampliação do olhar sobre a temática. Tal estratégia abre o discurso a novos sentidos, favorecendo "pontos de fuga" e relançando "os equívocos" da língua. (PÊCHEUX, 2008 [1983]). Trazer à discussão o paradoxal é, então, uma estratégia de alerta, algo que nos favorece a atenção e o aprofundamento da queixa. Neste sentido, trazemos a seguir seis extratos de queixas relatadas nas fichas de triagem que apontariam para o contraditório.

Menina de doze anos com queixa de dificuldade de aprendizagem, encaminhada pela escola, trazendo já à triagem relatório escolar. Relatório escolar fala em "desatenção, desinteresse, dificuldade em aprender e analfabetismo funcional”. (segundo informações colhidas (sic) - relatório escolar). Ao mesmo tempo encontramos no relato da família "aprendeu a ler com a explicadora". A família a considera leitora, mas a escola não. O que estariam compreendendo como leitura? Que significados possui a aprendizagem no contexto familiar?

Menino de sete anos com queixa de desatenção, isolamento, sem amigos e de pouca conversa, segundo a escola.

O aluno apresenta dificuldades em apropriar-se dos conceitos básicos para a aquisição de uma boa aprendizagem, em concentrar-se e em compreender comandos. Ao participar das atividades em grupo tem dificuldade em interagir com os colegas. O aluno expressa-se oralmente com muita dificuldade, aparenta desânimo constante e muita falta de interesse. (sic - relatório escolar).

Já na triagem a mãe relata que "em casa o menino fala até demais" (sic ficha de triagem). A diferença marcante nos ambientes diferenciados apontaria para dificuldade de aprendizagem como suspeita o relatório escolar, ou haveria 
algo na dinâmica do ambiente escolar que não faz sentido para esta criança? Se a expressão oral é difícil, por que em casa ele fala sem dificuldades?

A questão da atenção aparece no caso de um menino de oito anos encaminhado pela escola com déficit de atenção. Segundo o relato da mãe, "no final do segundo ano, escola e professores perceberam que ele era muito desatento, tirava boas notas, compreendia bem a matéria, porém não anotava nada no caderno e quando saía da sala, dizia se perder no colégio e não voltava para a sala". (sic - ficha de triagem). Se a atenção não compromete em nada a aprendizagem, estaríamos no registro do déficit? Qual a importância para a referida escola em copiar no caderno e sua função, se aparentemente não impacta na aprendizagem?

Menino de doze anos encaminhado pela escola por agitação. "Mudou de escola há quatro anos e desde então está mais agitado. O paciente relata que não gosta da escola atual, gostava da anterior. Já ganhou medalha de melhor aluno na anterior". (sic - ficha de triagem). Aqui de forma clara nota-se uma mudança em relação às diferentes escolas. Neste caso a agitação seria algo a se tratar na saúde mental, algo a ser medicado? Ou poderia ser resultado do enlaçamento da criança ao discurso da escola?

Os dois últimos relatos, encaminhados pela escola, chamam atenção por individualizar, centrar a questão da atenção e agitação predominantemente no polo da criança, o que justificaria o encaminhamento para a saúde mental. Já no discurso da criança e da família aparece uma firme referência ao dispositivo escolar, de modo mais geral. Uma leitura mais apressada da queixa poderia, portanto, reduzir uma questão mais ampla a uma patologia individual, mascarando uma tensão que envolveria o próprio dispositivo escolar.

A expectativa da família em relação à aprendizagem é algo a se considerar, como no caso de um menino de dez anos que a mãe apresentou queixa por causa de dependência escolar: "A mãe diz que o filho está com as mesmas dificuldades escolares das outras crianças, mas acha que ele devia estar melhor por já ter feito esta série". (sic - ficha de triagem). Neste caso, a dificuldade apontada parece situar-se na família e não na aprendizagem da criança propriamente dita, visto que o problema não é aprender, mas a defasagem entre a imagem de aprendente da mãe e o que a criança realiza.

Já na informação contida no relatório escolar, de um menino de oito anos levado pela família com queixa de não saber ler e escrever, encontramos um impasse encontrado pela escola. "Foi solicitado à criança escrever uma frase; não identificou a palavra escrita". (sic - ficha de triagem). "Recorre à memória e à criatividade para solucionar os problemas, a ponto de obter bons resultados em testes caso leiam para ele". (sic - relatório escolar). "Apesar de gostar da escola e mostrar-se interessado, começa a ficar evidente sua frustração". (sic - relatório escolar). O impasse apontado pelo relatório escolar poderia ser 
desdobrado em: como continuar gostando da escola se nela se espera aprender, mas isto não vem acontecendo?

Como podemos ver nas queixas recolhidas a partir das fichas de triagem, as questões que envolvem a inserção e permanência na escola, longe de apontarem apenas para o que parece ser uma dificuldade de aprendizagem, indicam uma teia complexa de significações e interveniências quanto ao mal-estar na escolarização. Se de um total de 92 casos encaminhados ao setor no primeiro semestre de 2012 com queixas escolares, 44 já aparecem nomeados com dificuldade de aprendizagem na triagem, isto chama atenção quando nos detemos mais tempo nos detalhes da queixa. Ou melhor, o que nos parece a partir da realização deste estudo exploratório é que, não poucas vezes, a nomeação do mal-estar como dificuldade de aprendizagem já de saída pode contribuir para a localização do problema "na criança" muitas vezes obnubilando uma visão mais abrangente da questão.

\section{À guisa de conclusão}

Iniciamos o presente artigo descrevendo a pesquisa piloto realizada no SPIA em 2012, relacionando-a a uma pesquisa maior que realiza estudo de casos em psicanálise e educação. Mostramos as principais queixas apresentadas em relação à escolarização relatadas ao profissional que realiza a triagem. A procura pelo serviço de saúde mental no período estudado confirmou em parte os achados por outros pesquisadores, já que apresentou prevalência de sexo e idade coincidente, mas o percentual de procura por motivos escolares menor do que o já referido. Em nosso caso, em torno de um terço do total dos que procuram o serviço, em contraposição à metade ou mais referida por alguns autores. (CABRAL; SAWAYA, 2001; ROMARO; CAPITÃO, 2003). O objetivo de estudar como chega a queixa escolar à saúde mental é possibilitar um olhar mais atento à relação saúde-educação no que tange à infância e adolescência. Ao mapearmos, na pesquisa exploratória, as formas como chegam as queixas à triagem notamos, como já mencionado, que não poucos são indicados pela escola. Como a escola está fazendo esta indicação e por que dirige esta demanda à saúde mental é um tema importante a ser pesquisado. Isso nos possibilita um aprofundamento do olhar do que estamos entendendo por "saúde" nas escolas e nas aprendizagens hoje.

Assim, o mote da pesquisa é o mal-estar na escolarização, recorrendo à noção de mal-estar na psicanálise, no sentido de ampliar o olhar sobre as queixas 
escolares. O mal-estar remete ao encontro do pulsional com a cultura, encontro do qual depende a constituição do sujeito e que está sempre por se fazer, o que na infância e na adolescência está bastante circunscrito ao contexto escolar. Pensar em mal-estar na escola é, portanto, pensar em um encontro entre os sujeitos que ali interagem atravessado por discursos que situam diferentes lugares e possibilidades de relação. Poder ouvir e trabalhar com esses discursos parece-nos então uma tarefa fundamental hoje, no sentido de promover deslocamentos de sentidos e lugares no que diz respeito ao recorrente sofrimento atrelado ao laço educativo, tão alardeado por pais, professores e alunos.

\section{REFERÊNCIAS}

BAUER, M.; GASKELL, G. Pesquisa qualitativa com texto imagem e som: um manual prático. Petrópolis, RJ: Vozes, 2002.

BOARINI, M. L.; BORGES. F. Demanda infantil por serviços de saúde mental: sinal de crise. Estudos de Psicologia, v. 3, n. 1, p. 83-108, 1998.

CABRAL, E.; SAWAYA, S. M. Concepções e atuação profissional diante das queixas escolares: os psicólogos nos serviços públicos de saúde. Estudos de Psicologia [on-line], v. 6, jul./dic. 2001. Disponível em: <http://www.redalyc.org/articulo.oa?id=26160203>. Acesso em: 14 jun. 2015.

CAMPEZATTO, P.; NUNES, M. L. T. Caracterização da clientela das clínicas-escola de cursos de Psicologia da região metropolitana de Porto Alegre. Psicol. Reflex. Crit. [on-line], v. 20, n. 3, p. 376-388, 2007. Disponível em: <http://dx.doi.org/10.1590/ S0102-79722007000300005>. Acesso em: 14 jun. 2015.

CATHARINO, T. Psicologia na Educação: contribuições da análise institucional. In: MACIEL, I. M. (Org.). Psicologia e Educação: novos caminhos para a formação. Rio de Janeiro: Ciência Moderna, 2001. p. 35-54.

FREUD, S. O mal-estar na civilização. In: FREUD, S. Obras Psicológicas Completas de Sigmund Freud. Rio de Janeiro: Imago, 1980 [1930]. v. XXI.

MELLO, M. F.; MELLO, A. A. F.; KOHN, R. (Orgs.). Epidemiologia da saúde mental no Brasil. Porto Alegre: Artmed, 2007.

PAIN, S. Diagnóstico e tratamento dos problemas de aprendizagem. Porto Alegre: Artes Médicas, 1985.

PATTO, M. H. S. A Produção do Fracasso Escolar: Histórias de Submissão e Rebeldia. São Paulo: Casa do Psicólogo, 1999. 
CARNEIRO, C.; COUTINHO, L. G. Infância e adolescência: como chegam as queixas...

PÊCHEUX, M. O discurso: estrutura ou acontecimento. Tradução de: Eni P. Orlandi. 5. ed. Campinas, SP: Pontes Editores, 2008 [1983].

ROMARO, R. A.; CAPITÃO, C. G. Caracterização da clientela da clínica-escola de Psicologia da Universidade São Francisco. Psicologia: Teoria e Prática, v. 5, n. 1, p. 111-121, 2003.

Texto recebido em 11 de setembro de 2014. Texto aprovado em 19 de junho de 2015. 